\title{
Inside and outside the black box: organization of interdependencies
}

\author{
Åke E. Andersson ${ }^{1}$ - Börje Johansson ${ }^{1,2}$ \\ Received: 8 May 2017 / Accepted: 10 August 2018 / Published online: 27 November 2018 \\ (c) The Author(s) 2018
}

\begin{abstract}
Production theory has remained substantially unchanged since the publication of the theory of production by Frisch (Theory of production, D. Reidel, Dordrecht, 1928; Nord 613 Tidskr Tek Økon 1:12-27, 1935). The theory is based on the idea of a firm deciding on the possible input and output combinations of a single unit of production. His theory was substantially copied in contributions by Carlson (A study on the pure theory of production, University of Chicago, Chicago, 1939) and Schneider (Einführung in die Wirtschaftstheorie. 4 Bände, Mohr, Tübingen, 1947), and later by practically all textbooks in microeconomics. The idea is to model the firm as a "black box" in which a finite number of externally purchased inputs are transformed into a finite number of outputs to be sold in the market(s). Most of the time, the prices are externally determined. Often, the production process is summarized by some simplified production function as, for example, in the form of a CES function. Another and conceptually richer approach is the formulation of an activity analysis model. In the latter case, simple internal interdependencies can be included. In this paper, we indicate how internal interdependencies can also be modeled within a special CES framework. In recent decades, there has been a remarkable growth in the number of production units of firms such as IKEA, Walmart and Apple to name a few such global networking firms. Most of the analysis of these network firms has been modeled by logistics and other operations-research analysts (Simchi-Levi et al. 2008) and to a limited extent by researchers in business administration schools. Very little has been done in economics. We propose a modeling approach consistent with the microeconomic theory.
\end{abstract}

JEL Classification D21 - D23 - D24 · D51 - D85 - F23 · F61 - L23 · R12

\footnotetext{
$凶$ Åke E. Andersson

Ake.Andersson@ju.se

Börje Johansson

Borje.Johansson@ju.se

1 Jönköping International Business School (JIBS), Jönköping University, Box 1026, 55111 Jönköping, Sweden

2 Royal Institute of Technology, Stockholm, Sweden
} 


\section{Introduction}

\subsection{Combining input and output vectors}

In science, economics, and engineering, a black box is a system which can be viewed in terms of its input and output (vectors), without any knowledge of its internal workings or the possible interactions with the environment. Its implementation is "opaque" or black. Observing and guiding the firm would then consist in manipulating the inputs so-as-to achieve the aspired output(s) (Fig. 1).

In most of the microeconomic theory, the firm is depicted as a "black box" consisting of a set of production activities or even a presumed production function with a finite set of inputs to be adjusted so-as-to generate a set of outputs corresponding to a maximal level of profits or some other measure of owner utility. The inputs controlled by the firm are then assumed to be put to their most efficient use without having a look "inside" the firm or "outside" in the relations with other economic agents, excepting for competition with other firms.

In Fig. 2, the output is affected by external factors, represented by $Z$. Solow (1957) made $A(Z)$ a function of the level of technology as reflected in the productivity trend as measured by a time series regression estimate. Later, this approach was complemented by estimates of the impact of the size of the region or the accessibility of the economy as reflections of conditions external to the firm or the local production system. It is now common to econometrically relate the total factor productivity (TFP) and its growth

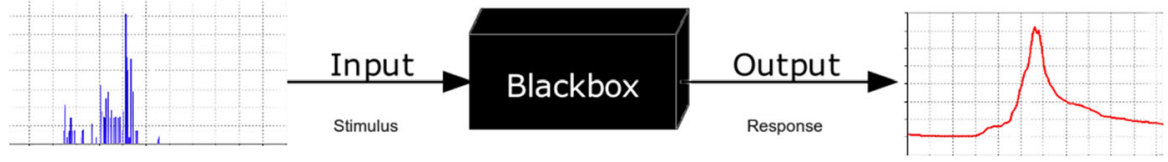

Fig. 1 Co-variation of input and output flows

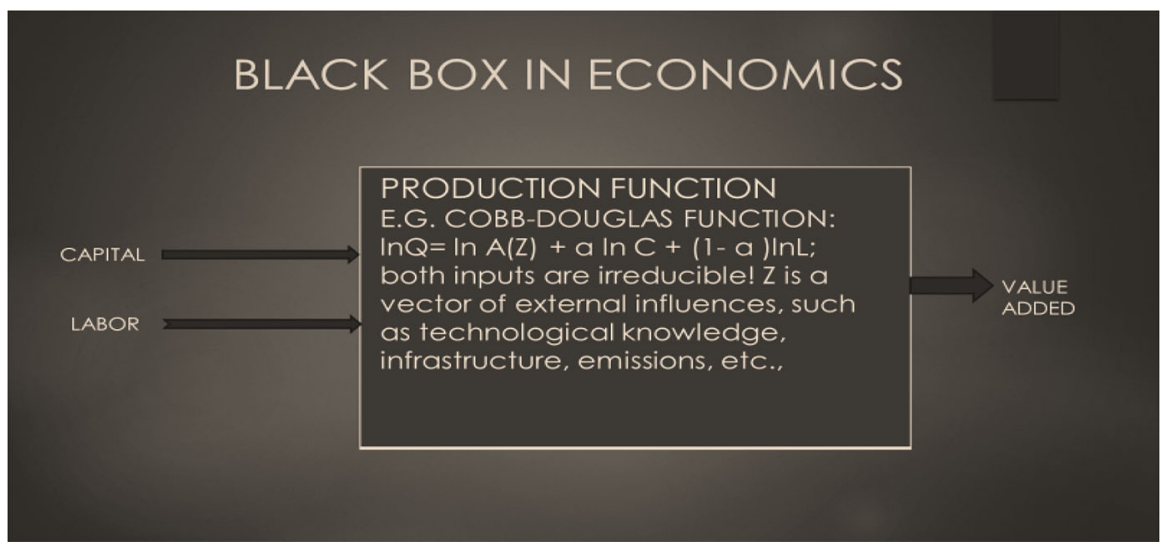

Fig. 2 Cobb-Douglas production function 
to some function of $Z$ (Cardarelli and Lusinyan 2015), i.e., to "explain" productivity by factors outside of firm owner's control (Lööf and Johansson 2014).

Coase (1937) was the first economist pointing out that in addition to production costs of the usual sort, one must also consider transaction costs inside and outside of the firm in explaining institutions such as a firm. He focused on the comparative transaction costs of alternative organizational structures, such as firms and markets. This theory was later extended by Oliver Williamson and became widely known as transaction-cost economics (Williamson 1989) or more broadly the economics of organization.

Coase (op.cit.) and later Demsetz (1968), Williamson (op.cit) and Beckmann (1977) opened the black box representation of the firm, claiming that an understanding of the evolution of firms requires an analysis of transaction costs and benefits inside and outside the firm.

Chenery (1949) and Smith $(1959,1961)$ extended the analysis beyond the black box by proposing a model of the firm based on engineering data, but this approach was not followed by him to any substantial extent. This approach was later adopted in several studies by Scandinavian economists (Forsund and Jansen 1983; Wibe 1977).

While the black box approach might be reasonable in the case of a single site firm, it becomes inadequate when analyzing modern multilocation network firms with production units located in hundreds or even thousands of globally distributed nodes. The black box approach is not easily adaptable to the analysis of network firms. If a firm is producing a homogenous output, there could be good reasons to allocate production between several identical plants operating on their own in regions, differing in cost of inputs. In this case, the decision rule is to allocate production so that the marginal cost of each plant equals marginal revenue of total output.

In a multilocation network firm producing heterogenous output, different spatially separated units have economic reasons to interact with each other with positive and negative consequences for the returns of the network firm, seen as a whole. The interactions will have an impact on productivity as well as the quality and pricing of the outputs as demonstrated below.

\subsection{The network firm in the post-industrial C-society}

The C-society is "post-industrial" by its orientation toward creativity, communication, knowledge, etc. It is now slowly establishing itself in some of the world's regions. Industrialism is being abandoned in those regions to allow knowledge, creativity, and innovations to take the center stage in economic life. The regions that are currently being integrated in the emerging global knowledge networking economy are all relatively well positioned in the air transportation, communication, and road networks. They are therefore well endowed with interaction capabilities. Compared with the rest of the world, these creative regions also have superior access to public scientific and private R\&D knowledge. Frequently, they contain a collection of diverse creative environments in universities, high-technology firms, and different cultural entities. Firms that rely on exploiting natural resources and the manual employments are being phased out in these regions, while new firms that rely on knowledge, networks and 
globally important institutions are creating a new economic structure. This transformation is creating substantial social and political tensions between regions, generations and occupational groups.

\subsection{Infrastructure supporting economies of scope}

Post-industrial firms exploit communication and transportation infrastructure, since it is an accessible, highly productive and profitable production factor. But, a successful use of new infrastructure requires of firms that they adapt organizationally as well as in their pattern of locations. The networks are now much denser than in the early industrial era. Together, the various networks also amount to a multi-layered, mutually reinforcing system. In the best case, a firm in a specific location can simultaneously take advantage of international and domestic flight connections, freeways and other roads, railways, sea transportation, and digital communication. Firms with great contact and transportation needs can achieve dynamic comparative advantages by locating in regions that have developed into central nodes in the new multi-layered networks. But, firms can also strengthen their comparative advantages even more by creating a new and more externally and internally interdependent network organization of their production and distribution system. Corporations producing and distributing material goods such as Walmart, Amazon, IKEA and the major ICT, pharmaceutical and auto manufacturers were among the first firms to discover the profit potential in using and adapting their organization to the new network potentials for more efficient product development, marketing, logistics and production. Network firms solely producing and distributing information-e.g., Google or Netflix —are subject to different network constraints and opportunities.

Manufacturing firms such as producers of pharmaceuticals, cars, and computers buy a wide variety of patented knowledge and knowledge-based components from subcontractors, which are used as inputs in the production of the final product. They are inherently networking firms that are heavily dependent on powerful transport and communication networks. These firms have also restructured the most to exploit the opportunities presented by the new arena. Amazon, Walmart, and IKEA are textbook examples of how the new networks have created economies of scope and scale.

Large-scale communication systems and transportation terminals are also afflicted with capacity utilization problems. Large airport terminals, for instance, are necessary to cope with temporarily large loads of passengers and cargos. At other times, the terminals seem desolate and incur high average and low marginal costs. Terminals are therefore also increasingly designed to achieve economies of scope.

A precondition for exploiting diversity is that it is possible to attract customers from a variety of localities. Economies of scope in production go hand in hand with economies of scope in the networks. When a corporation decides to take advantage of the capacity of the networks, it will systematically harness the resource of diversity. IKEA offers a great variety of furnishings that attracts a wide cross section of society to visit its stores in a wide cross section of societies including Europe, America, Australia, China, Singapore, Korea, and Taiwan. But, the new diversity is not confined to the range of products or the variability in the customers' appearance, age, or income. 
Behind the diversity that is visible to customers, there is an even greater diversity in the production and logistical structures that characterize the new corporate networks. The economics of diversity makes it possible to meet the pent-up demand of very small groups and to make use of highly specialized, but unusual skills. Networking firms thereby equalize the employment and consumption conditions of different regions. These firms invariably operate under conditions of monopolistic competition.

To illuminate the management issues introduced in Sect. 1, the paper is outlined as follows. Section 2 investigates productive advantages of collaboration inside the firm, describes its interactivity with the firm environment in product development, and identifies a basic interplay between knowledge creation and economies of scale. Section 3 focuses on management of multilocation firms and characterizes collaboration between units of a network firm and makes precise the role of large scale in production and distribution. In addition, the section suggests that that management employs a "split-vision approach" when making the transmission from hierarchy to self-organization principles. Section 4 presents concluding reflections.

\section{Collaboration, product attributes and interaction}

Section 2 presents productive advantages that arise due to collaboration inside the firm, the value of altering product attributes, and benefits from economies of scale.

\subsection{The productive advantages of collaboration within the firm}

Let us assume that the product of two different types of researchers or scientists of an R\&D-dependent firm (e.g., physicists and engineers, $l_{i}$ ) is determined by a CES production function with a $\rho$ larger than zero, then this form corresponds to a general average equation as shown and analyzed by Hardy et al. (1934, Chap. 2):

$$
q=\left(\alpha l_{1}^{\rho}+\beta l_{2}^{\rho}\right)^{1 / \rho}
$$

Let us first assume that $\rho=1$. Then $q$ is a linear function of $l_{i}$, which means that production is independent of cooperation between the two types of scientists. Any value $1>\rho>0$ implies that there are advantages of cooperation. To illustrate this phenomenon, assume that $\rho=1 / 2$. Then we have the quadratic form as given in (2):

$$
q=\left(\alpha l_{1}^{0.5}+\beta l_{2}^{0.5}\right)^{1 / 0.5}=\left(\alpha l_{1}^{0.5}+\beta l_{2}^{0.5}\right)^{2}=\alpha^{2} l_{1}+\beta^{2} l_{2}+2 \alpha \beta\left(l_{1} l_{2}\right)^{0.5}
$$

The function in (2) illustrates that the combination of the two categories of labor inputs matters, and we can see that if research category 2 is excluded, then output is reduced to the level $q_{1}=\alpha^{2} l_{1}$. Exclusion of category 1 instead brings about $q_{2}=$ $\beta^{2} l_{2}$, and now we can conclude that $q$ in formulas (1) and (2) satisfies $q>q_{1}+q_{2}$, which by the Hölder inequality theorem means that the compound output from the two collaborators exceeds the sum of the single outputs. 
The production function outlined in (2) sheds light on the task of management of collaboration inside a production unit, where the output may vary from knowledge services to homogenous goods. It offers a background to the quadratic production function in formula (3), where the collaborative network contains interaction pairs such as (i) employees of category $l_{i}$ and $l_{j}$, (ii) employees $l_{i}$ and machines $m_{j}$ (e.g., computers), and (iii) machines $m_{h}$ and $m_{k}$. In this setting, we may outline a production function of the following kind:

$$
q=\sum_{i} a_{i} l_{i}+\sum_{i} b_{j} m_{j}+\sum_{i j} a_{i j}\left(l_{i} l_{j}\right)^{0.5}+\sum_{i k} a_{i k}\left(l_{i} m_{k}\right)^{0.5}+\sum_{h k} b_{h k}\left(m_{h} m_{k}\right)^{0.5}
$$

where $a$ corresponds to $\alpha^{2}$ in (2), $b$ corresponds to $\beta^{2}$ and so on. The collaboration advantage parameters $a_{i j}, a_{i k}$, and $b_{h k}$ can be made decreasing functions of the distances between the collaborating entities. This means that the advantages of collaboration would favor an initial expansion in the home market.

If there would be possibilities of part-time collaboration within the firm, a solution to such a quadratic maximization problem with real assignment values is quite easy to find.

\subsection{The value of product attributes}

The early industrial firms were usually established for the exploitation of some natural resource. A large part of the exploited and refined natural resource was thereafter exported to other countries with other natural advantages regarding specialized production and export. In the initial stages of industrialization, industrial firms were mostly specialized in mining and technologically simple manufacturing, which achieved profitability through economies of scale (large production volumes), but normally with little value added in the process of transforming raw materials into final consumer goods.

In monopolistic competition, the value and price of a product to the user are determined by its attributes (or characteristics). Every product is best conceived of as a bundle of attributes, where the value of each attribute is ultimately decided by the buyers. We may also recognize how different combinations of attributes give rise to different product varieties, where each supplier of varieties may select a profitmaximizing price for each variety (Andersson and Johansson 2012). Empirical studies of the housing and car markets have revealed that a considerable number of attributes may be decisive for the willingness to pay, which has a strict impact on the actual price. The amount of knowledge and information that is used by the producer will have an impact on the constituent product attributes, thereby influencing the value of the product to potential buyers.

The knowledge-intensive industries have abandoned quantitative growth for qualitative product development (Andersson et al. 2013). The unit value of most products is increasing. This is paralleled by a greater use of knowledge and information and with a greater variety of components and subcontractors. The greater complexity of the products tends to be accompanied by a more educated work force, a greater reliance 
on computer hardware and software, and a greater demand for inputs collaboratively designed and produced in processes requiring face-to-face contacts with leading component manufacturers around the world.

Knowledge and information are concentrated into a limited number of locations. Examples are cities of design activities such as Milan or Paris. Examples of centers of technological knowledge are San Francisco, and Boston. Access to such centers of research, fashion and design is important for decisions on the marketing, pricing and on structure and volume. Decision about location of production determines the associated accessibility.

\subsection{Knowledge, value of goods and economies of scale}

The willingness to pay for a good, $P$, can be assumed to depend upon knowledge in the form of scientific ideas, consumer fashions, patented products, or techniques embodied in component goods from other regions than the home region of the firm. This can be functionally represented by $P$-functions, being dependent upon the inflow of ideas coming from other nodes of the global network. Such ideas are used as inputs, to be embodied in the products to be marketed by the firm, where knowledge is defined as information structured according to some theoretical principle. It is assumed that accessing knowledge of importance for user willingness to pay, $P$, requires personal face-to-face contacts.

In this subsection, we outline a maximization model that depicts how a node $i$ selects a product value $P_{i}$ and quantity $Q_{i}$ while using knowledge accessed from the local node $i$ and from external nodes $j \neq i$. It is further assumed that the $P$-functions are differentiable everywhere and concave with respect to inputs of knowledge. The volume of production is assumed to be regulated by a conventional concave and differentiable production function with local resources as the inputs. The central component is the vector $K^{i}=\left(K_{1 i}, \ldots, K_{i i}, \ldots, K_{n i}\right)$, where $K_{j i}$ denotes the interactive knowledge (or information) flow from node $j$ to node $i$, and where $K_{i i}$ represents the local knowledge available in node $i$.

The optimal flows of local and interactive inputs can be determined by the maximization procedure formulated in (4), where the quantity $q$ is replaced by $Q$ which is a function of $M$ - and $K$-resources

$$
\operatorname{Max} V_{i}=P_{i}\left(K^{i}\right) Q_{i}\left(M_{i}, K_{i i}\right)-\sum_{j} \omega_{j i} K_{j i}-w_{i} M_{i}
$$

$K^{i}$ a vector of knowledge (or information) flows from nodes $j$ to node $i ; P_{i}\left(K^{i}\right)$ quality as measured by willingness to pay for a unit of output from node $i$; $\omega_{j i}$ price of knowledge (or information), including unit transaction and communication cost. $K_{i i}$ knowledge (recipes, human capital or information) available in node $i . M_{i}$ material capital services in node $i ; \omega_{i i}$ price of knowledge (human capital), in node $i ; w_{i}$ required return to material capital in node $i$

Conditions of maximization are of two kinds: 
Marginal productivity conditions:

$$
\begin{gathered}
P_{i}\left[\partial Q_{i} / \partial M_{i}\right]=w_{i} ; \quad i=1, \ldots, n \\
P_{i}\left[\partial Q_{i} / \partial K_{i i}\right]+Q_{i}\left[\partial P_{i} / \partial K_{i i}\right]=\omega_{i i}, \quad i=1, \ldots, n
\end{gathered}
$$

\section{Marginal interactivity conditions:}

$$
Q_{i}\left[\partial P_{i} / \partial K_{j i}\right]=\omega_{j i} ; \quad i=1, \ldots, n ; \quad j \neq i
$$

where condition (7) states that the marginal impact of knowledge from node $j$ on the price of good $i$ should at the optimum equal the price of knowledge $j$ divided by the scale of production in node $i, Q_{i}$.

The marginal interactivity conditions in (7) indicate that there are economies of scale in interaction at distances, implying that the larger the firm, the more globalized it would be in terms of size and spatial scope of its interaction pattern. Under fairly general technological assumptions, the interactions could follow gravity functions (Andersson and Persson 1993).

The production and the use of new knowledge and information (especially uniform global advertising) unavoidably benefit from economies of scale, which is explained by the potential collectiveness of knowledge and information. In other words, knowledge and information are inexhaustible in their ability to be used repeatedly. And every reuse implies a reduction in the cost of creativity. Small bankrupted auto makers such as Saab or Rover often complained about the heavy financial burden of their R\&D spending, which however was unavoidable if they had wished to remain competitive. Researchintensive firms such as Pfizer or AstraZeneca are for this reason continuously searching for feasible mergers, cooperation agreements and alliances, to share indivisible R\&D costs among a greater number of products and customers.

There are, of course, ways to reduce the need for knowledge-induced large-scale corporations. Sometimes it is possible to share R\&D costs by using consulting firms that work for the benefit of several firms in the same industry. An influential knowledge service firm is Microsoft, which has reduced or eliminated the costs of developing software for an enormous number of firms.

But this type of R\&D is hardly feasible for the development of entirely new products. Firms obviously wish to improve their competitiveness by offering new product varieties with a new set of attributes, in which case it is unlikely that they would like to share their newly acquired knowledge with other firms. One way to deal with this problem is to share the costs with researchers without commercial interests of their own. This is arguably one of the reasons why firms in research-intensive industries, for example the pharmaceutical industry, often locate in close proximity to universities, medical schools, and public or non-profit research institutes (Andersson et al. 2010).

Marketing is another activity beside R\&D where economies of scale will remain important. The marginal cost of producing a copy of a brochure or a catalog is almost negligible if a couple of thousand copies have already been produced. Commercials that are screened on television channels or social media such as YouTube with a worldwide reach have large fixed costs and minuscule variable costs. Many of the advertising 
media are only profitable for very large firms. In addition, information-handling networks internal to firms are also associated with substantial economies of scale. Firms that operate in many markets need computerized communications to attain a sufficiently efficient production. For some types of productions, reliability considerations force firms to design complementary networks to the general-access ones. Such production implies high fixed costs, leading to economies of scale and difficulties for new start-ups. Another development strategy is the so-called modularization, where modules are combined in alternate ways to obtain scope without compromising scale (Sköld and Karlsson 2013).

\section{Management of multilocation firms}

The presentation in the previous section is here widened to include network firms with many units of production forming multilocation firms. Such company groups would in most cases be engaged in monopolistic competition, reflecting the importance of advertising and locational choice on demand.

\subsection{Collaboration between different units of a multilocation firm}

Consider a large network firm with its production nodes of location in many regions around the world. Each one of the production/distribution units is dependent upon the contacts with one (or many) of the firm's centers. This implies that the collaboration net advantages will depend on distance between the units as wells as the gross advantage of collaboration.

However, if the assignment must be integer valued — because of indivisibilities-we are faced with the quadratic assignment problem as first formulated by Koopmans and Beckmann (1957). This problem has turned out to be extremely hard to solve, even for a moderately large number of collaborating units.

With $1 / 2>\rho>0$ in model (2), the advantages of collaboration are larger than given by the quadratic form. These larger advantages of collaboration would not improve the possibilities of finding integer valued solutions to these highly nonlinear assignment problems.

However, most of the global network firms choose to have collaborating units of different sizes, on different markets. For example, IKEA has two of the largest units located in Stockholm and Shanghai, while many units located in other regions with less demand are quite small and thus adapted to the local conditions. Apple similarly has developed a network with differently sized production and distribution units in various parts of the world.

The models (1)-(3) and (4)-(7) can be adapted to solve this multi-facility design problem, taking into account the advantages and costs of collaboration between the differently sized units of the firm network of production and distribution activities and the pricing advantage of absorbing knowledge or information from different markets. In this model, we look at the simplified case of colocation into two markets. A further simplification is that we assume that all relevant market knowledge (or information) 
is available in the two market locations considered. We consider the case when $\rho=$ 0.5 , which yields the production function

$$
\begin{aligned}
& Q_{1}=\alpha_{11}^{2} K_{11}+\alpha_{21}^{2} K_{21}+\beta_{12} f\left(d_{12}\right) K_{11}^{0.5} K_{21}^{0.5} ; \\
& Q_{2}=\alpha_{12}^{2} K_{12}+\alpha_{22}^{2} K_{22}+\beta_{21} f\left(d_{21}\right) K_{12}^{0.5} K_{22}^{0.5} ;
\end{aligned}
$$

$\beta_{i j}=2 \alpha_{i i} \alpha_{i j}$ and $f$ is a nonincreasing positive function of distance (d). Moreover, the size of total material and non-material capital is represented by $K_{i j}$ and $K_{j j}$ in node $j$. The conditions for an efficient allocation will determine the output and the price (and quality) levels, $P_{1}\left(I_{1}\right)$ and $P_{2}\left(I_{2}\right)$, where $I_{1}=\left(I_{11}, I_{21}\right)$ and $I_{2}=\left(I_{12}, I_{22}\right)$, and where each element $I_{i j}$ is a variable of a unit in a location and its information on international, interregional and local accessibility, and its institutions and its characteristics of the consumers. This knowledge or information can thus be in terms of institutional conditions, fashion, quality demand, etc., factors that would influence the choice of pricing strategy in the two locations. This is given in formulas (9)-(10).

The decision problem of the firm is illustrated by its search for max profits $V$ of the network corporation considering the expansion of production units 1 and 2 , such that $\operatorname{Max} V=P_{1}\left(I_{11}, I_{21}\right) Q_{1}\left(K_{11}, K_{21}\right)+P_{2}\left(I_{12}, I_{22}\right) Q_{2}\left(K_{12}, K_{22}\right)-\omega_{11} I_{11}-\omega_{21} I_{21}$ $-\omega_{12} I_{12}-\omega_{22} I_{22}-\mu_{11} K_{11}-\mu_{21} K_{21}-\mu_{12} K_{12}-\mu_{22} K_{22}$. This implies that the network firm augments sales income, $P_{1} Q_{1}+P_{2} Q_{2}$, by manipulating $I_{1}$ and $I_{2}$ (e.g., product development) and by selecting capacities $K_{1}=K_{11}+K_{21}$ and $K_{2}=K_{12}+$ $K_{22}$.

For given price levels, $P_{1}$ and $P_{2}$, the size of output adjusts in response to the price of capital $\mu_{11}$ and $\mu_{21}$ in node 1 , and $\mu_{22}$ and $\mu_{12}$ in node 2 (material and non-material) as specified in (9):

$$
\begin{gathered}
P_{1}\left(\partial Q_{1} / \partial K_{11}\right)=\mu_{11} ; \quad\left(\partial Q_{1} / \partial K_{21}\right)=\mu_{21} ; \\
P_{2}\left(\partial Q_{2} / \partial K_{12}\right)=\mu_{12} ; \quad P_{2}\left(\partial Q_{2} / \partial K_{22}\right)=\mu_{22} ;
\end{gathered}
$$

where the $\mu$-variables equal the exogenously determined price of capital services supplied in the nodes. For this case of two locations of the firm and $\rho=1 / 2$, we have four equations to be solved as a system. These equations reflect the decision to determine the capital to be used by the unit of production itself, subject to the level of capital used by the other units (8)-(9). The choice would be dependent on the marginal impact on the price from an increase in the market information:

$$
\begin{array}{ll}
Q_{1}\left(\partial P_{1} / \partial I_{21}\right)=\omega_{21} ; & Q_{1}\left(\partial P_{1} / \partial I_{11}\right)=\omega_{11} ; \\
Q_{2}\left(\partial P_{2} / \partial I_{12}\right)=\omega_{12} ; & Q_{2}\left(\partial P_{2} / \partial I_{22}\right)=\omega_{22}
\end{array}
$$

where $\omega_{j i}$ denotes the cost of transferring information from node $j$ to node $i$. The equations show that there are economies of scale in acquiring information. The four equations in (10) illuminate how market information from node 1 influences the price of output (products) supplied from node 1 and 2 . Likewise, the same type of information from node 2 has an influence on the output price of the supply from node 1 and 2 . There 
are 8 equations to be solved for the $8 K$ - and $I$-variables. These will then determine the $Q$ - and $P$-parameters.

The context of the allocation solution as characterized in (8)-(10) is the distribution of the total material and non-material capital, $K$, its link-specific price levels in node $i$ as given by the $\mu_{j i}$-variables, and the information-transfer costs $\omega_{j i}$. Moreover, the variables $\omega_{i j}$ are mostly functions of geographical or cognitive distance and of the $K_{i}$ and $I_{j}$ variables. Furthermore, the total capital allocated to the units will be determined by the equations at levels that are dependent on the transaction and transport cost and the pricing impact of the levels of market information, $I_{j}$. If the center of the network firm would be located in region (node) $i$, a location of a second firm $(j)$ would be considered if the addition of firm $j$ would increase the net profits of the network firm as a whole.

The multilocation network firms should not be looked upon as a production and distribution system in a stable equilibrium. These network firms would be calculating the profitability of different potential new locations to be rank-ordered. The ranking of locational profitability would then determine the pattern of investment in new locations as illustrated by the expansion paths of IKEA, Volkswagen, H\&M, Zara and other multilocation firms (Baraldi 2003).

\subsection{Large scale in production and distribution}

The advantages of large isolated production units or bureaucracies are diminishing in the production and distribution of goods or services. A characteristic of early industrialism was its almost total dependence on sea and rail freight. The economic benefits of large, homogeneous cargo flows, which were caused by the inflexible and indivisible links of rail transportation networks and the relatively large sizes of cargo ships, were most easily obtained if the production was organized according to the same principles. Mass transportation by sea or rail encouraged mass production.

The new finely meshed multi-layered networks with their myriads of relatively small automobiles, trucks, and airplanes supported by ITC networks no longer guarantee that large factories or office buildings are the most efficient. Diversity, dispersion, and decentralized networks mutually reinforce their respective advantages.

Two tendencies are crystallizing. The message of one of these is that "small is beautiful." Ever denser networks make dispersed production, contacts, and transport profitable. The advantage of a multitude of distribution units depends on the durability of the products. As an example, a firm like Walmart with numerous perishable goods has 11,500 shops worldwide, while IKEA selling goods with substantial durability has 340 shops. The new network opportunities are especially significant for firms like Volkswagen with its 120 plants producing goods with frequent service needs, since efficient service production depends on recurring cooperation between producers and customers.

The second tendency points in the opposite direction. The increasing importance of research, product development, marketing, and other creative activities means that firms focus on the expanding and globally dispersed pool of knowledge and educational resources in their development strategies. Creative activities feed on economies of 
scale, since the use of a new production recipe does not prevent it from being used again. Even though it may have cost millions of dollars to develop the new recipe, it can still be made profitable if it is reused for a sufficiently large number of times. This means that expensive investments in creative research and development are profitable only if the production volume is sufficiently large. If the design of a new car model costs $\$ 1$ billion and the sales volume is one million cars, the design cost per car will be $\$ 1000$. If the producer instead sells four million cars, the cost of developing the car will be spread among a greater number of car buyers, who will only have to contribute $\$ 250$ per car to cover the development cost. Information and marketing are subject to the same indivisibilities and fixed costs. The increasing economic importance of creative knowledge, information, and marketing inevitably entails a growth in scale economies and dependence on the global accessibility of knowledge.

\subsection{The management employing split vision}

Which one of the two conflicting tendencies will gain the upper hand? As it happens, this question obscures the real problem. The relevant question is whether the persistence of two conflicting tendencies will induce a reorganization of economic life, which will enable firms to use smallness and economies of large scale as compatible complements. Such a parallel development, toward enterprises that allow efficiency to be realized in small as well as large settings, requires a split vision.

A split vision is necessary in chess, politics, hockey and other games where operative, tactical, and strategic goals and occurrences must be dealt with simultaneously. A successful chess master, politician, or hockey player must take both small-scale and large-scale factors into account at the same time. Small-scale speed and precision must be coupled with a strategy regarding the slow development or transformation of the overarching structure. The same need for splitting one's vision is found in many of the experimental sciences. Frequently, a multifold of rather trivial experiments is conducted at the same time as the slow elaboration of testable hypotheses and a theoretical synthesis is taking place. Success in science, politics, and games all call for a split vision.

Firms need the same type of simultaneity for handling the advantages of reducing the size of production and distribution units, while at the same time realizing economies of scale in the production of knowledge and information. Networking firms such as IKEA and Microsoft are examples of how to resolve the simultaneous advantages of economies of large and small scale. These firms exploit the global economies of scale inherent in the infrastructure and in knowledge production, while at the same time exploiting the advantages of relying on small units for assembly, distribution, and customer services. Smallness in production and distribution increases their ability to adapt to local differences in terms of variations in $I_{i}$. As observed earlier, Sköld and Karlsson (2013) suggest that modularization provides an avenue for combining product scope and production scale. 


\subsection{From hierarchies to self-organization}

The ever more polycentric corporations face several unavoidable organization problems. Unlike their predecessors of the industrial era, these firms will never be able to design a sustainable organization plan. In the industrial society, the organization of firms was largely predetermined by the scarcity of education and means of communication. Hierarchical organizations were then the only rational organizations. Stable hierarchies are still common in the organization plans of old firms and bureaucracies.

The education and communication conditions are now entirely different compared to the industrial age. The duration-of-education difference between the most highly educated and the average person has shrunk from six to one and a half times in the advanced market economies. The general theoretical competence is now widely distributed among the employees of a large corporation, while knowledge of local and regional conditions is superior in the local and regional locations. There is no longer a self-evident central authority. Moreover, information in contrast to new knowledge is now almost entirely disembodied. It can simultaneously be made available without any distance-dependent costs in all the nodes of the global network.

When the advantages of mass production and mass distribution are diminishing, at the same time as the returns to scale in knowledge production, information, and marketing are increasing, it follows that the overall size of firms as well as the number of local units should increase. In the new economy, it is profitable to let the local units use their superior knowledge of local product and labor markets. Centralization can be confined to strategic objectives, research, development, and the setting of minimal standards regarding short-term and long-term profits. Everything else is more efficiently planned for at the local level. Even in theoretical terms, it is obvious that it is hardly optimal to construct a detailed long-term organization plan that regulates the interactions among hundreds or thousands of distribution and production units.

If a firm consists of ten units, such planning might still be possible. In such a firm, there will be 45 possible links $(=10 \times 9 / 2)$ between the units that are to be organized according to plan. If we instead assume that we are dealing with a large multinational networking corporation with one thousand constituent production, distribution, and development units, we will have to take account of $n(n-1) / 2$. With 1000 units, this implies 499,500 possible links $(=1000 \times 999 / 2)$. Among these half a million possible relationships, it would be impossible to explicitly plan anything by a strict hierarchy of commands. This would imply a hierarchical organization into five levels with a span of control of 10-15 units as a feasible organization. However, such a plan would only make sense in an entirely stationary world. But in the post-industrial economy, where markets are continuously changing through research-led competition between firms, it is essential that the internal organization of firms is undergoing constant adaptation or change. The leaders of the new networking corporations have for this reason largely given up using comprehensive organization plans and centralized budgeting.

The only organization principle that is likely to survive in the new economy is selforganization guided by appropriate incentives. Leadership will increasingly consist of the ability to create a corporate culture, an incentive structure, and constitutional rules governing the interaction of units within the firm. Product development programs will 
be designed in cooperation with the development and marketing units. The managers will subsequently decide the bottom line for different time horizons. But, the individual production and distribution units will independently organize their interactions with other units, as long as these interactions are compatible with the corporate culture and to the extent that the resulting synergies contribute to improved profitability, growth, and other expressions of overall success. Organization and reorganization will no longer be a bureaucratic concern, but rather an ongoing self-organization on an internal (intra-firm) market, which leads to improved competitiveness on the external, interfirm, market. The spontaneous growth of global scientific cooperation and competition shows that principles of self-organization have become superior to the meticulously designed plans of central decision makers and their bureaucrats.

\section{Conclusions}

Microeconomic analysis was long focused on the decision problems of owners of a single-plant firm working in isolation from other firms. The firm was then assumed to be represented by an input-output function, often a Cobb-Douglas or a constant elasticity of substitution production function or an activity analysis formulation. These simplifications made econometric estimation feasible.

Differences between firms in total factor productivity stimulated research into the impact of factors external to the firm. These factors, external to the individual firm decision processes, became a focus of much, primarily empirical, research where the external economies were represented by the level of technological knowledge, accessibility to other firms, "economic milieu," clustering of firms and other more or less measurable factors.

\subsection{Inside and outside links of a firm}

In this essay, we have made a basic distinction between (i) a single-plant firm and (ii) a multi-plant or multilocation firm, with a focus on the latter, which is referred to as network firm. A firm's outside links are based on contracts which often are partly implicit and relate to decision making about input and output deliveries. These links are present for both single-plant and multi-plant firms, where the management of the latter makes use of internal links to govern the interdependencies between the different units or plants of each network firm.

With the distinctions above, we may contemplate solution concepts that apply to a firm's external (outside) links and to its internal (inside) links. The external links associate with contracts and would thereby be components of a non-cooperative equilibrium, if such a solution can be realized. The cooperative solution for the internal links and nodes of a network firm is different in nature and depicts the network as a coalition of the firm units (plants), where the formation of the coalition is the outcome of the management's design and re-design over time. This type of design often involves "super additivity," which in this presentation corresponds to "advantage of collaboration." In view of this, we observe that a non-cooperative equilibrium safeguards itself, 
and because of this it can be thought of as self-organized. The cooperative solution does not safeguard itself and must instead get support from management governance.

\subsection{Stepwise evolution of a multilocation firm}

Although single-plant firms still have an important role in most regions and countries, the dynamics of businesses have increased the relative importance of multi-plant firms such as Pfizer, Apple, Volkswagen, Walmart and IKEA. These firms have grown to have from a couple of hundred to tens of thousands of production, assembly and distribution units. These multi-plant corporations have not decided upon the total structure of the firm but have rather evolved in a stepwise fashion with additions of single units whenever they have contributed to profitability.

Walmart is an example of a network firm where new decisions applied at each stage of evolution of the corporation. Half a century ago, it was a rule of thumb in the USA of not opening a discount store unless the city had a population of more than 100,000 inhabitants. Walmart decided against this rule of thumb and started to open new discount stores in smaller cities around the south-west of USA. This strategy was quite successful, because their new stores had created local non-contestable monopolies in the short term. And they could succeed as long as Walmart had the financial resources necessary for higher speed of establishment than potential competitors. They had demonstrated the power of a dynamic preemptive strategy in the growth of network firms. In recent decades, this preemptive strategy has been at work in the growth of Walmart units in Asia, Latin America and in parts of Europe (Djeddour 2011; Pindyck and Rubinfeld 2013). However, with the location to larger regions Walmart has increasingly been forced into monopolistic competition strategies.

Each one of the added units could of course operate as an isolated entity, serving the region of location and using resources locally supplied. Belonging to a network of interacting units of production would be an attractive option if the productivity of the production unit (e.g., plant) would be increased by interacting with one or many other units fused into a network firm. In the analysis, we are using a special variant of the CES production function, allowing for isolation as well as interaction of plants. A Cobb-Douglas specification would not be useful, because of irreducibility of inputs.

An addition of a unit to the network firm would then be considered if the sum of two-part interaction profits would be positive. Adding a unit to a network firm would not only generate profits by production interaction. If a firm specialized in interior decoration would create a unit in the city of Milano, they would be aware of latest trends in furniture design at a much faster rate than if the unit would have been established in Omaha. This better information would potentially increase the willingness to pay for the furniture in distribution outlets in other firm locations. We have modeled these market interactions by assuming that each unit of production and distribution would experience a positive impact on their quality improvements and consequential pricing opportunities from information on market variables in the separate locations. A network firm would thus be expanding in size and diversity of locations, given that each added unit of production, assembly and distribution would imply an increase in profitability from intra-firm cooperation and use of market information. Modeling 
network firms requires an understanding of interaction between units of production and of the markets of location.

Open Access This article is distributed under the terms of the Creative Commons Attribution 4.0 International License (http://creativecommons.org/licenses/by/4.0/), which permits unrestricted use, distribution, and reproduction in any medium, provided you give appropriate credit to the original author(s) and the source, provide a link to the Creative Commons license, and indicate if changes were made.

\section{References}

Andersson M, Johansson B (2012) Heterogenous distributions of firms sustained by innovation dynamics-a model with empirical illustrations and analysis. J Ind Compet Trade 12:239-263

Andersson ÅE, Persson O (1993) Networking scientists. Ann Reg Sci 27:11-21

Andersson M, Johansson B, Karlsson C, Lööf H (2010) Multinationals in the knowledge economy-a case study of AstraZeneca in Sweden. In: Repositioning Europe and America for growth. The role of governments and private actors in key policy areas. Berlin LIT Verlag, pp 233-278

Andersson ÅE, Andersson DE, Matthiesen CW (2013) Öresundsregionen: den dynamiska regionen (Öresound: The Dynamic Metropolis). Dialogos, Stockholm

Baraldi E (2003) The places of IKEA: using space as a strategic weapon in handling resource networks. Department of Business Studies, Uppsala University

Beckmann MJ (1977) Management production functions and the theory of the firm. J Econ Theory 14(1):1-18

Cardarelli R, Lusinyan L (2015) US total factor productivity slowdown: evidence from the US States. IMF

Carlson S (1939) A study on the pure theory of production. University of Chicago, Chicago

Chenery HB (1949) Engineering production functions. Q J Econ 63:507-531

Coase RH (1937) The nature of the firm. Econ New Ser 4(16):386-405

Demsetz H (1967) Toward a theory of property rights. Am Econ Rev 57(2):347-359

Demsetz H (1968) The cost of transacting. Q J Econ 82(1):33-53

Djeddour M (2011) Strategic management lecture. Grenoble Graduate School of Management, New York

Forsund FR, Jansen ES (1983) Technical progress and structural change in the Norwegian primary aluminum industry. Scand J Econ 85(2):113-126

Frisch R (1928) (mimeographed in Norwegian), 1965, Theory of production. D. Reidel, Dordrecht (Translated by R.I. Christophersen)

Frisch R (1935) The principle of substitution, an example of its application in the chocolate industry. Nord Tidskr Tek Økon 1:12-27

Hardy GH, Littlewood J, Polya G (1934) Inequalities. Cambridge University Press, Cambridge

Koopmans TC, Beckmann M (1957) Assignment problems and the location of economic activities. Econometrica 25(1):53-76

Lööf H, Johansson B (2014) R\&D strategy, metropolitan externalities, and productivity. Ind Innov 21:141-154. https://www.tradegecko.com/blog/ikeas-inventory-management-strategy-ikea

Pindyck R, Rubinfeld D (2013) Microeconomics, 8th edn. Pearson, London

Schneider E (1947-1972) Einführung in die Wirtschaftstheorie. 4 Bände. Mohr, Tübingen

Simchi-Levi D, Kaminsky P, Simchi-Levi E (2008) Designing and managing the supply chain: concepts, strategies, and case studies. McGraw-Hill, New York

Sköld M, Karlsson C (2013) Stratifying the development of product platforms: requirements for resources, organization and management styles. J Prod Innov Manag 30(1):62-76

Smith VL (1959) The theory of investment and production. Q J Econ 73(1):61-87

Smith VL (1961) Investment and production-a study in the theory of the capital-using enterprise. Harvard University Press, Cambridge

Solow R (1957) Technical change, and the aggregate production function. Rev Econ Stat 34:312-320

Wibe S (1977) En teknisk produktionsfunktion för järnframställning i masugn (An engineering production functions for ironmaking in blast furnaces). Umeå Economic Studies

Williamson OE (1989) Transaction cost economics Chapter 3 in handbook of industrial organization, vol 1. North Holland, Amsterdam, pp 135-182 